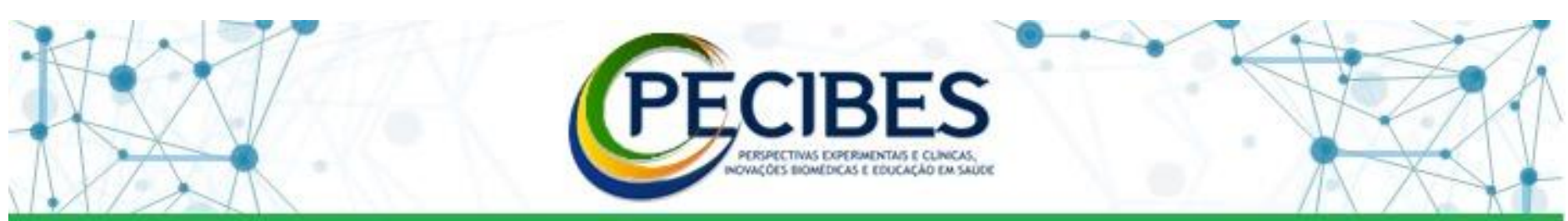

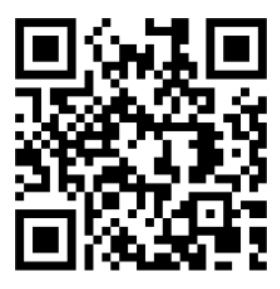

http://www.seer.ufms.br/in dex.php/pecibes/index

*Autor correspondente:

Yann Zurutuza, Universidade

Federal de Mato Grosso do

Sul -UFMS. E-mail do autor:

zurutuza.yann@gmail.c om

Descritores: Fadiga muscular. Aptidão física. Força de mão. Esportes.

Keywords: Muscle fatigue. Physical fitness. Hand strength. Sports. Palabras clave: $\quad$ Fatiga muscular. Aptitud física. fuerza de la mano. Deportes.

\section{Efeito da imersão em diferentes temperaturas na recuperação aguda da força muscular e do desempenho físico em atletas de judô}

Effect of immersion in different temperatures on muscle strength recovery and physical performance in judo athletes

Yann Zurutuza ${ }^{1}$, Carlos Alberto Eloy Tavares ${ }^{1}$, Karla de Toledo Candido Muller ${ }^{2}$, Silvio Assis de Oliveira-Júnior ${ }^{3}$.

1. Mestrando, Programa de Pós-Graduação em Ciências do Movimento (INISA/UFMS), Campo Grande - MS.

2. Doutor(a) pelo Programa de Pós-Graduação em Saúde e Desenvolvimento na Região CentroOeste(FAMED/UFMS), Campo Grande - MS.

3. Docente, Programa de Pós-Graduação em Ciências do Movimento (INISA/UFMS), Campo Grande- MS.

Introdução: Devido à realização de várias lutas em um mesmo dia, a exigência física que o atleta passa é muito alta, podendo resultar em fadiga muscular. Para o rendimento não ser prejudicado é importante uma recuperação muscular de curta duração. Objetivo: Compara o efeito da imersão da água fria e da água quente na recuperação de curta duração da força muscular e no desempenho físico em atletas de judô. Metodologia: Este estudo foi aprovado pelo Comitê de Ética em Pesquisa em Seres Humanos (CEP/UCDB; parecer 3.063.294, CAAE 03447818.0.0000.5162). Participaram da pesquisa 14 atletas de judô de Campo Grande/MS, com idade entre 18 e 25 anos, com no mínimo quatro anos de prática esportiva e que estavam em atividade. Foram realizados três procedimentos experimentais: recuperação passiva. imersão em água fria a $5^{\circ} \mathrm{C}$. imersão em água quente a $40^{\circ} \mathrm{C}$. A coleta de dados ocorreu em três momentos, um para cada protocolo experimental (a ordem de execução dos protocolos foi aleatorizada), e com intervalo de uma semana entre os momentos. Os indivíduos realizaram a avaliação da força de preensão palmar, utilizando um dinamômetro eletrônico, e o desempenho físico se deu com uso de um handgrip ajustável, o teste de esforço teve o tempo cronometrado até a exaustão. Resultados: Avaliando a força de preensão, todos os grupos apresentaram diferença significativa (p\&lt;0,05) comparando a força inicial com a força pós-fadiga e a força pós-fadiga para as forças de recuperação. apenas o grupo controle não apresentou diferença significativa (p\&gt;0,05) entre a força de preensão inicial e as forças de recuperação. já avaliando o desempenho, apenas a imersão em água fria apresentou queda do desempenho inicial para ofinal (p\&lt;0,05). Conclusão: A recuperação passiva se mostrou mais eficaz na recuperação de curta duração da força muscular, recuperando a força de preensão inicial. A recuperação passiva e a imersão em água quente foram eficazes mantendo o desempenho subsequente. 